\title{
Power System Security Assessment and Remedial Measures based on the on-line Dynamic Security Assessment System
}

\author{
Dajiang Wang ${ }^{1, a, *}$, Haoming $\mathrm{Hu}^{1}$, Xiao $\mathrm{Chen}^{3}$, Jie $\mathrm{Li}^{2}$, Yaming $\mathrm{Ge}^{2}$, Jinmin Cheng ${ }^{2}$, Xi Chen ${ }^{2}$, \\ Yi Cao ${ }^{2}$, Qi Wang ${ }^{2}$, Wei Fu ${ }^{2}$, Zhaoyang $\operatorname{Yan}^{2}$, Gang $\mathrm{Li}^{2}$, Yuchen $\mathrm{Hao}^{2}$, Tao Zhu ${ }^{2}$ \\ ${ }^{1}$ State Grid Jiangsu Electric Power Company Research Institute, 1 Power Road, Nanjing, China \\ ${ }^{2}$ State Grid Jiangsu Electric Power Dispatching and Control Centre, 215 Shanghai Road, Nanjing, \\ ${ }^{3}$ State Grid Jiangsu Electric Power maintenance branch company, 58 Suyuan Road, Nanjing, China \\ awangdj1983@163.com \\ *corresponding author
}

Keywords: on-line analyse, dynamic security assessment, intelligent scheduling system, remedial measures

Abstract: The on-line dynamic security assessment system introduced in this paper
calculates and assesses power system using high performance parallel cluster and the real
time on-line data obtained by intelligent scheduling system, achieving a leap from the off-
line analysis to the on-line analysis of the power grid. The main structure, function and
calculation process of the dynamic security assessment system are briefly introduced, the
safety and stability analysis of power grid after serious failures is taken as example, the
calculation results show that the dynamic security assessment system can calculate the
power grid and propose the corresponding auxiliary decision-making measures timely and
effectively, enhancing the emergency handling capacity of power dispatchers in emergency
situations, it plays an important role in ensuring the security and stability of power system.

\section{Introduction}

With the increasing demand for power in the world due to rapid social and economic development, the scale of modern interconnected power system is increasing and the structure is more stronger, with the improvement on economy and reliability of the system operation, however, at the same time, it faces various challenges from new problems[1,2]. Several blackouts that have been experienced throughout all over the world during recent few years show that local power disturbance may lead to large-area cascading failures once again[3,4]. Therefore, improving the security and stability analysis level has become one of the important means of ensuring the operation of the power system.

The off-line calculation manner is used for the traditional security analysis of power system, but there is difference between the selected typical mode and actual operation condition, which makes the results tended to conservation in most cases; thus, the on-line security analysis method gains extensive attention both domestic and abroad [5-11]. Aiming at the new demand for the 
development of power grid, on-line security and stability analysis technology is need urgently to overcome the insufficiency of traditional off-line calculation, adopting on-line dynamic security assessment to power grid and finding problems in all operation modes, putting forward prevention decision measures, thus to enhance the efficiency of the dispatchers, and effectively improve the capacity of reining operation of bulk power system.

Therefore, implementation of the dynamic security assessment (DSA) based on smart dispatching system and the calculation analysis based on the real-time data collected by the energy management system is of important significance. In this paper, the structure and function module of DSA is briefly introduced first, the stability analysis calculation process of DSA is analysed then, and the security and stability analysis of a certain area power system after fault is carried out as example. The results show that the DSA system plays an important role in assisting scientific decision-making for the dispatchers.

\section{Introduction to DSA}

Based on smart dispatching D5000 system, the DSA responsible for security and stability analysis of power grid within the dispatching management scope, and the overall structure, basic function and calculation flow of DSA will be briefly introduced.

\subsection{Data source}

The data source is the basis for on-line analysis and calculation. The DSA system based on D5000 system first automatically acquires the on-line calculation data issued uniformly by higher dispatching centre through the interface with the dispatching support system, including static model and parameters, real-time flow data, and forms a complete data set that can reflect the real-time operation condition of the power grid through data integration of local dynamic model and parameter for loads and units, to provide complete data source for on-line security and stability assessment.

\subsection{The structure and basic function of DSA}

The main structure of DSA system is shown in Figure 1.

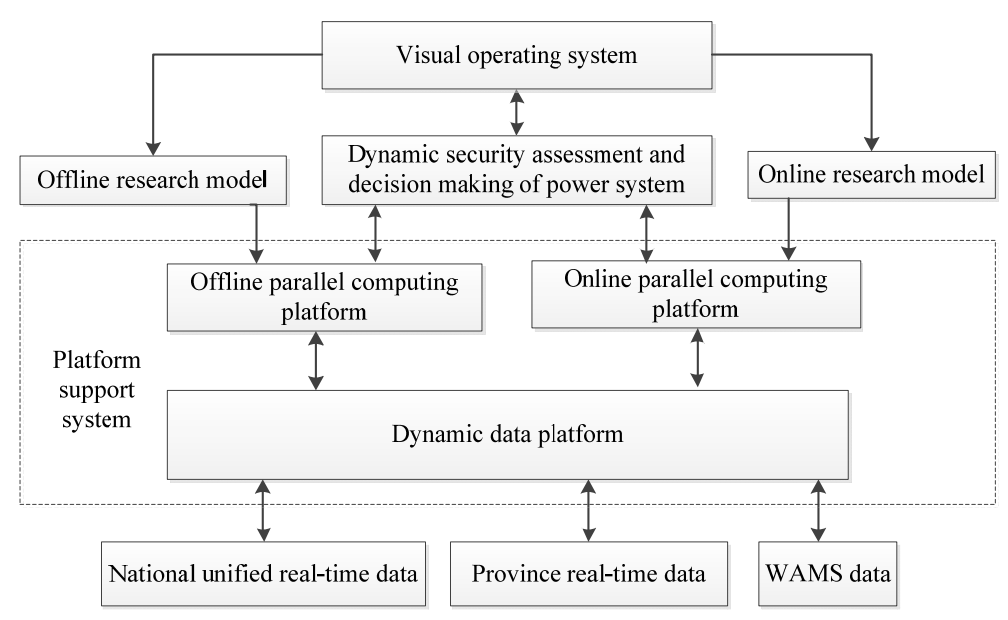

Figure 1 The main structure of DSA.

Main hardware configurations constituting the system in Figure 1 include compute node cluster, dispatching management server, data interface server, network connection switch, and engineer's 
workstation, etc., and each part coordinates with each other for working, completing various calculation and analysis needed or allocated by the system, and returning the results to the humanmachine interface.

\subsection{The analysis flow of DSA}

The DSA system gets the calculation data needed through integration of relevant data such as equipment parameters, fault set, and real-time information of power grid, forming the reasonable on-line power flow data conforming to actual operation condition of power grid. Then, six types of calculations are carried out, including basic state flow scanning, static security analysis, transient stability analysis, dynamic stability analysis, voltage stability analysis, and short-circuit current analysis. At the same time, the stability margin of the key section of the power grid is calculated, and the operation mode with low margin is warned, the auxiliary decision measures are proposed. The overall calculation and analysis flow is shown in Figure 2[12].

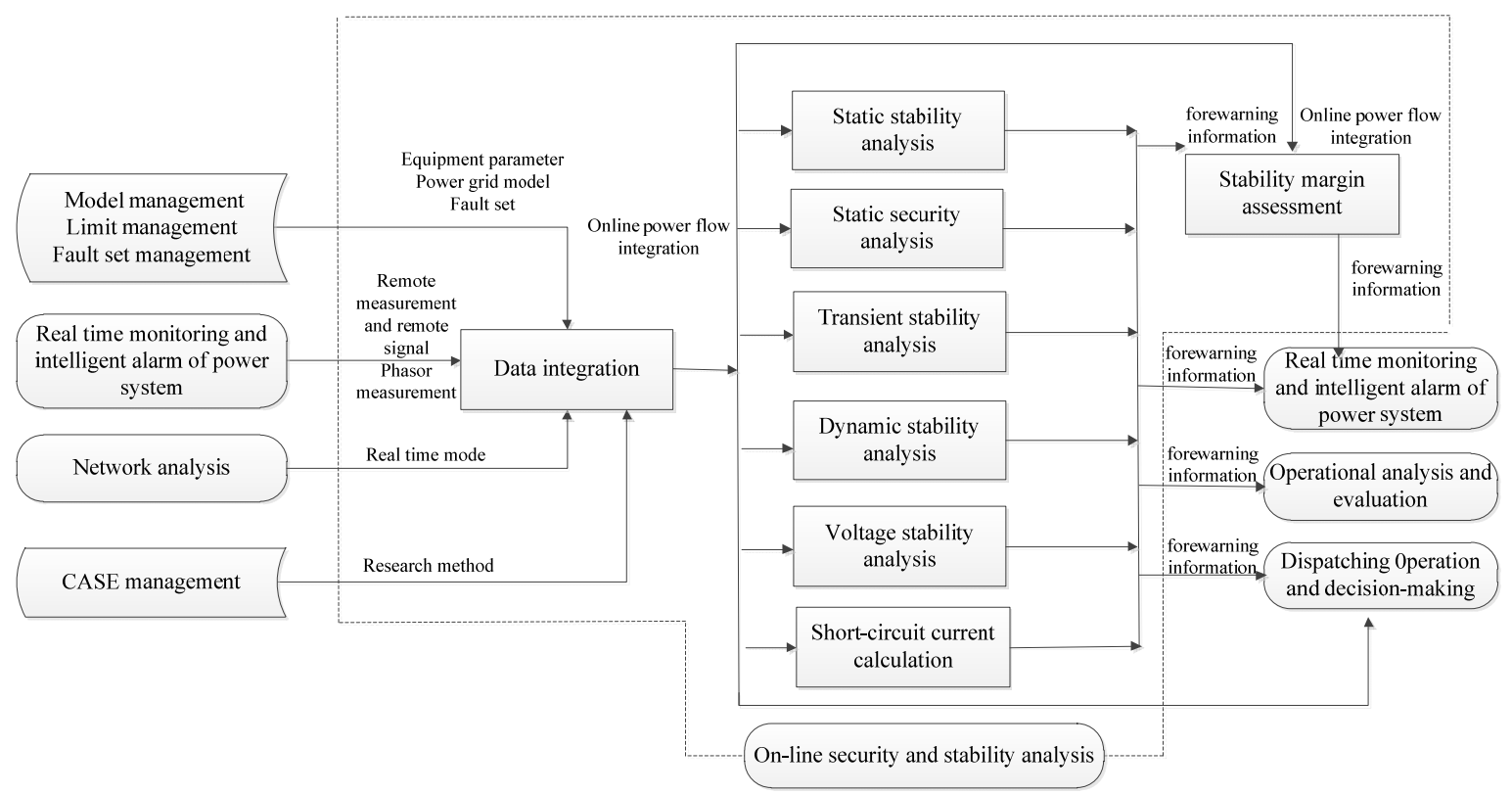

Figure 2 The calculation and analysis flow of DSA.

\subsection{Calculation mode of real-time state and research state}

The calculation modes of DSA system include two modes: real-time calculation module and research calculation module. The real-time module is to realize on-line tracking of actual operation of power grid, whose calculation is started periodically. Six types of calculation analysis and prevention control decision-making measures are carried out for the power grid every $15 \mathrm{~min}$ regularly, to realize the visualized monitoring and on-line auxiliary decision-making,providing the dispatcher with the prevention control measures for the power grid under the current operation mode, and giving the stability limit and dispatching strategy.

The research calculation module is started by events, in which the data concerned by dispatchers is selected, to study static, transient and dynamic problems existing in the system in details, search the cause of security and stability problems of the system, and propose the fundamental method of solving these problems, thus to achieve the purpose of optimizing the operation, and improving the stable and economic operation under the current operation mode of power system. The difference 
between the two calculation modes is the different start-up period, and the remaining functions are same.

\section{Application of DSA to power system}

From 1 p.m. to 3 p.m. on June 23, 2016, strong rainfall, heavy wind happened in the northern part area of Jiangsu province, with severe convective weather such as strong thunder, short-time heavy rainfall, hail, and thunderstorms. The power grid was severely affected, including tripping of two $500 \mathrm{kV}$ lines, multiple $220 \mathrm{kV}$ lines and $110 \mathrm{kV}$ lines.

As a result, multiple substations in this area operated by single-line feeding, in which $220 \mathrm{kV}$ YN-DY double lines, DY-HX line, and HX-XY line were tripped. After tripping of the lines, the power grid was weakened with operation risk, and part of the power grid after the fault is shown in Figure 3.

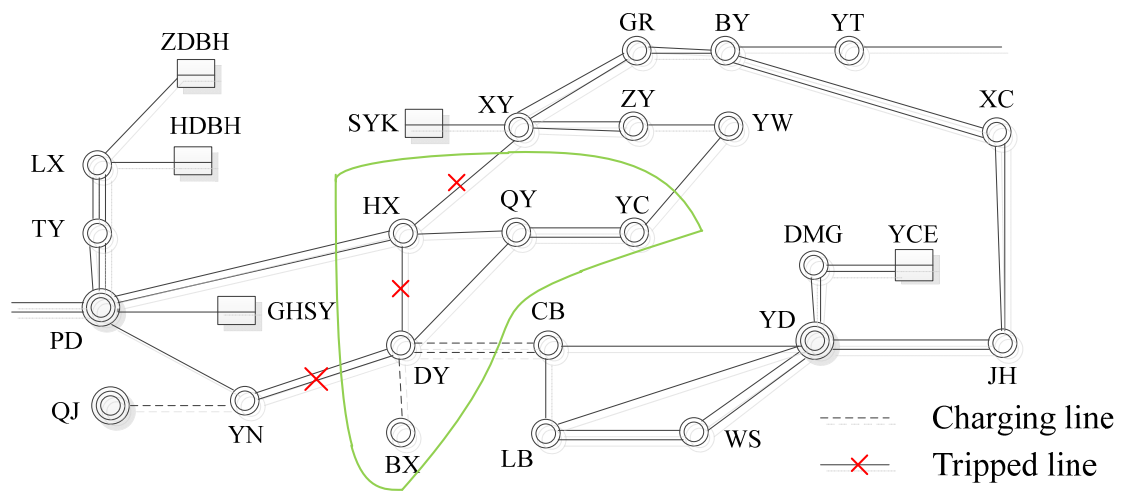

Figure 3 The part of the power grid after fault.

It can been seen that multistage feeding mode is formed in the power grid, five $220 \mathrm{kV}$ substations including HX, QY, DY, BX and YC were connected with the other part of power system by PD-HX double lines and YC-YW line, as shown in the green solid line part in Figure 3. The security analysis engineer immediately selected the data issued by the superior dispatching centre at 3 p.m. on June 23, 2016 as the basic analysis data for the DSA system, and six types of calculations were automatically carried out.

After the security analysis of DSA system, it was found that there was static security problems, without problems such as transient stability, dynamic stability, or short-circuit current exceeding limit. The calculation results are shown in Table 1, and detailed static security calculation results are shown in Table 2 and Table 3:

Table 1 Results of dynamic security assessment.

\begin{tabular}{|c|c|c|c|}
\hline \multicolumn{2}{|c|}{ Overload safety analysis of equipment } & \multicolumn{2}{c|}{ Static voltage security analysis } \\
\hline Safety margin & $-15.92 \%$ & Safety margin & $-2.51 \%$ \\
\hline Overload equipment & YC-YW line & Bus & DY substation /220kV.bus \\
\hline The worst fault & $\begin{array}{c}\text { PD-HX double lines } \\
\text { tripping }\end{array}$ & The worst fault & $\begin{array}{c}\text { PD-HX double lines } \\
\text { tripping }\end{array}$ \\
\hline
\end{tabular}


Table 2 Equipment overload results of static security assessment.

\begin{tabular}{|c|c|c|c|c|}
\hline Fault components & $\begin{array}{c}\text { Equipment exceeding } \\
\text { limit }\end{array}$ & $\begin{array}{c}\text { Current after } \\
\text { fault (A) }\end{array}$ & $\begin{array}{c}\text { Rated } \\
\text { current (A) }\end{array}$ & $\begin{array}{c}\text { Safety } \\
\text { margin (\%) }\end{array}$ \\
\hline PD-HX double lines tripping & YC-YW line & 1787.46 & 1542.00 & -15.92 \\
\hline PD-HX double lines tripping & TW-YL line & 1866.72 & 2390.00 & 21.89 \\
\hline PD-HX double lines tripping & YF line & 600.83 & 857.00 & 29.89 \\
\hline PD-HX double lines tripping & XY line & 1077.54 & 1542.00 & 30.12 \\
\hline
\end{tabular}

Table 3 Static voltage security assessment results.

\begin{tabular}{|c|c|c|c|c|}
\hline Fault components & Bus & $\begin{array}{c}\text { Voltage after } \\
\text { fault }(\mathrm{kV})\end{array}$ & $\begin{array}{c}\text { Low-limited } \\
\text { voltage (kV) }\end{array}$ & $\begin{array}{c}\text { Safety } \\
\text { margin (\%) }\end{array}$ \\
\hline PD-HX double lines tripping & DY substation /220kV.bus & 203.76 & 209.00 & -2.51 \\
\hline PD-HX double lines tripping & HX substation /220kV.bus & 205.05 & 209.00 & -1.89 \\
\hline PD-HX double lines tripping & QY substation /220kV.bus & 205.59 & 209.00 & -1.63 \\
\hline PD-HX double lines tripping & YC substation/220kV.bus & 209.31 & 209.00 & 1.87 \\
\hline
\end{tabular}

The above calculation results show that the power grid after the disaster has static security problems, and after tripping of PD-HX double lines, YC-YW line will exceeds the limit, and 220kV bus voltage of three stations including DY, HX and QY will exceeds the lower limit.

The auxiliary decision-making measures given by DSA are to reduce active load of YC substation by $99.5 \mathrm{MW}$, and reactive load by $16.73 \mathrm{MVar}$; active load of QY substation by $17.97 \mathrm{MW}$ and reactive load by 5.22MVar. The stability calculation results after the auxiliary decision-making measure are adopted are shown in Table 4.

Table 4 Results of after comprehensive assistant decision.

\begin{tabular}{|c|c|c|c|}
\hline & & Before adjustment & After adjustment \\
\hline \multirow{3}{*}{$\begin{array}{l}\text { Overload safety } \\
\text { analysis of } \\
\text { equipment }\end{array}$} & Safety margin & $-15.92 \%$ & $7.75 \%$ \\
\hline & The worst fault & PD-HX double lines tripping & PD-HX double lines tripping \\
\hline & $\begin{array}{l}\text { Overload } \\
\text { equipment }\end{array}$ & YC-YW line & YC-YW line \\
\hline \multirow{3}{*}{$\begin{array}{c}\text { Static voltage } \\
\text { security analysis }\end{array}$} & Safety margin & $-2.51 \%$ & $0.3 \%$ \\
\hline & The worst fault & PD-HX double lines tripping & PD-HX double lines tripping \\
\hline & Bus & DY substation /220kV.bus & DY substation /220kV.bus \\
\hline
\end{tabular}

Under the circumstance that the power grid was seriously damaged and a large of loads were lost, power resources are extremely important for after-disaster emergency rescue as well as production and living, and the operation of load shedding is certainly not appropriate. Due to the area connection lines including DY-CB double lines and YN-QJ line were in charged state for reserve, thus it is decided that these three lines are putted into operation after discussion, in order to strengthen the power grid, and the grid after mode adjustment is shown in Figure 4. 


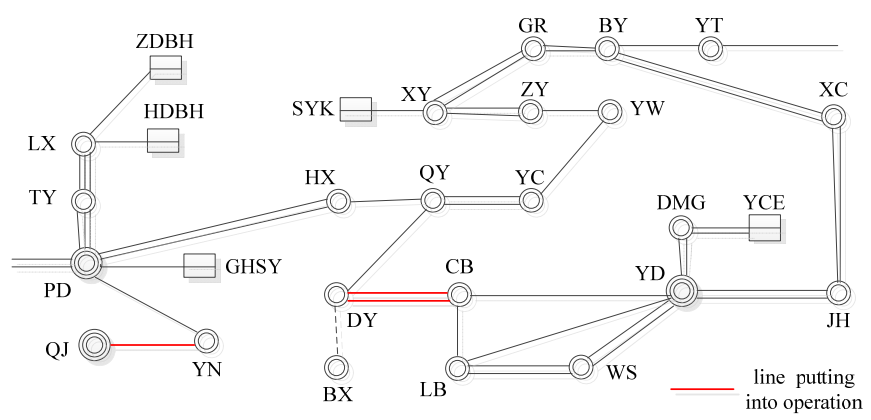

Figure 4 The part of the power grid after operation mode adjustment.

After the operation mode adjustment, the power grid structure was strengthened. After tripping of PD-HX double lines, security margin of YC-YW line is $5.63 \%$, security margin of bus voltage in DY, HX, QY are $3.25 \%, 4.62 \%, 5.12 \%$, respectively. Thus the operation risk after tripping of PD$\mathrm{HX}$ double lines is eliminated.

\section{Conclusions}

In this paper, the DSA system based on D5000 smart dispatching system is introduced, and then the security and stability calculation of power grid in a certain area after mega-disaster is taken as an example. The results show that the DSA system can rapidly and effectively realize on-line security analysis, find the weaknesses in real-time operation of the power grid, and provide the dispatchers with the effective technical support and auxiliary decision making measures for regulating the power grid, which plays an important role in actual operation of power system. However, the auxiliary decision making measures given by DSA is inadequate at present, the regulation measures only includes the starting and shutdown of units, adjustment and control of loads. In most cases, some measures are only feasible in theory, but the operation of reserve connection lines, load transfer and other operation mode adjustment, are not feasible by the DSA now, which needs further optimization and improvement in future.

\section{References}

[1] Tang Yi, Chen Bin, Pi Jingchuang, et al. Analysis on absorbing ability of receiving AC system for UHVDC hierarchical connection to AC grid [J].Proceedings of the CSEE,2016,36(7):1790-1800.

[2] Wu Ping, Chen Hao, Zhao Bing, et al. Study on interaction and stability characteristics of bundled wind-PVthermal power transmitted with AC/DC system [J].Power System Technology,2016,40(7):1934-1942.

[3] TANG Yong, BU Guangquan, YI Jun.. Analysis and Lessons of the blackout in Indian power grid on July 30 and 31, 2012[J]. Proceedings of the CSEE,2012,32(25):167-174.

[4] MAO Anjia, ZHANG Geli, LV Yuechun, et al. Analysis on large-scale blackout occurred in South America and North Mexico interconnected power grid on Sept. 8, 2011 and lessons for electric power dispatching in China[J].Power System Technology,2012,36(4):74-78.

[5] Yan Jianfeng,Yu Zhihong,Tian Fang,et al. Dynamic security assessment \& early warning system of power system [J].Proceedings of the CSEE,2008,28(34):87-93.

[6] Zheng Chao,Hou Junxian,Yan Jianfeng, et al. Functional design and implementation of online dynamic security assessment and early warning system [J].Power System Technology,2010,34(3):55-60.

[7] Yan Xu, Zhao Yang Dong, Jun Hua Zhao,et al. A reliable intelligent system for real-time dynamic security assessment of power systems [J]. IEEE Transactions on Power System 2012;27(3):1253-1263. 
[8] Miao He, Junshan Zhang, Vijay Vittal. Robust online dynamic security assessment using adaptive ensemble deci-sion-tree learning [J]. IEEE Transactions on Power System 2013;28(4):4089-4098.

[9] Sun Shuming, Xie Chang, Lv Ying, et al. Power system online security and stability analysis application modes [J].Power System Technology, 2015,39(10):2875-2881.

[10] Chengxi Liu, Kai Sun ,Zakir Hussain Rather,et al. A systematic approach for dynamic security assessment and the corresponding preventive control scheme based on decision trees [J].IEEE Transactions on Power System 2014;29(2):717-730.

[11] Janath Geeganage, U. D. Annakkage , Tony Weekes et al. Application of energy-based power system features for dynamic security assessment[J].IEEE Transactions on Power System 2015;30(4):1957-1965.

[12] National electric power dispatching center. Theory and application of online analysis for bulk power grid[M]. Beijing: China Electric Power Press,2014: 112-118. 